\title{
Automatic measurement of touch and release angles of the fetlock joint for lameness detection in dairy cattle using vision techniques
}

\author{
A. Pluk, ${ }^{*}$ C. Bahr, ${ }^{*}$ A. Poursaberi, ${ }^{*}$ W. Maertens, $\dagger$ A. van Nuffel, $†$ and D. Berckmans ${ }^{\star 1}$ \\ ${ }^{*}$ Division of Measure, Model and Manage Bioresponses (M3-BIORES), Katholieke Universiteit Leuven, Kasteelpark Arenberg 30, \\ B-3001 Leuven, Belgium \\ †Institute for Agricultural and Fisheries Research, Technology and Food Science Unit-Agricultural Engineering, B-9820 Merelbeke, Belgium
}

\begin{abstract}
This paper describes a synchronized measurement system combining image and pressure data to automatically record the angle of the metacarpus and metatarsus bones of the cow with respect to a vertical line, which is useful for lameness detection in dairy cattle. A camera system was developed to record the posture and movement of the cow and the timing and position of hoof placement and release were recorded using a pressure sensitive mat. Experiments with the automatic system were performed continuously on a farm in Ghent (Belgium) for $5 \mathrm{wk}$ in September and October 2009. In total, 2,219 measurements were performed on 75 individual lactating Holstein cows. As a reference for the analysis of the calculated variables, the locomotion of the cows was visually scored from recorded videos by a trained observer into 3 classes of lameness [53.5\% were scored with gait score (GS)1, 33.3\% were scored with GS2, and $9.3 \%$ were scored with GS3]. The contact data of the pressure mat and the camera images recorded by the system were synchronized and combined to measure different angles of the legs of the cows, together with the range of motion of the leg. Significant differences were found between the different gait scores in the release angles of the front hooves, in the range of motion of the front hooves, and in the touch angles of the hind hooves. The contact data of the pressure mat and the camera images recorded by the system were synchronized and combined to measure different angles of the legs of the cows, together with the range of motion of the leg. With respect to the classification of lameness, the range of motion of the front hooves (42.1 and $42.8 \%)$ and the release angle of the front hooves (41.7 and $42.0 \%$ ) were important variables. In $83.3 \%$ of the cows, a change in GS led to an increase in within-cow variance for the range of motion or the release angle of the front hooves. In $76.2 \%$ of the cows,
\end{abstract}

Received May 18, 2011.

Accepted October 10, 2011.

${ }^{1}$ Corresponding author: daniel.berckmans@biw.kuleuven.be an increase in GS led to a decrease in range of motion or an increase in release angle of the front hooves.

Key words: lameness detection, dairy cattle, joint angle, image processing

\section{INTRODUCTION}

Lameness in dairy cattle is an increasing economic and animal welfare problem. It has a negative effect on milk production (Warnick et al., 2001; Green et al., 2002), body condition, and reproductive performance (Booth et al., 2004; Peake et al., 2011). It presents an animal welfare problem of concern because pain and prolonged discomfort occur (Scott, 1989). Early detection of lameness is important for effective treatment and prevention. Timely detection may prevent lameness from developing into a chronic condition (Clarkson et al., 1996). Locomotion scoring systems have been used to quantify lameness occurrences in dairy cows. Some systems assessed quality of locomotion and posture by visual observations (Sprecher et al., 1997; Thomsen et al., 2008). Flower and Weary (2006) concluded that a numerical rating system was valid and reliable for identifying hoof pathologies. Manual scoring of dairy cow lameness is time-consuming and expensive when performed continuously on large-scale farms (Whay and Main, 1999).

When assessing the quality of locomotion, veterinarians and ethologists consider several lameness indicators, such as back posture, head bob, leg swing, and step overlap. The correlation between the individual indicators and the overall locomotion score was evaluated by Rajkondawar et al. (2002), Poursaberi et al. (2010), and Pluk et al. (2010). Electronic techniques are increasingly used for lameness detection in the dairy industry. Herlin and Drevemo (1997) used highspeed cameras to investigate locomotion in cows. The claw's ground contact sequence on the treadmill using high-speed cinematography was investigated by Meyer (2007). Flower et al. (2005) investigated kinematic gait variables using motion analysis software. An automatic lameness detection system based on ground reaction 
force was developed by Tasch and Rajkondawar (2004). In research for detection of equine lameness, Buchner et al. (1996) investigated the flexion and extension of limb joints with induced lameness, concluding that hyperextension of the fetlock and flexion of the coffin joint were the most sensitive indicators for fore- and hind limb lameness.

The objective was to describe a synchronized measurement system combining video and contact data to automatically record joint angles in dairy cattle. The angle of the metacarpus and metatarsus bone of the cow was measured with respect to a vertical line.

\section{MATERIALS AND METHODS}

A camera system was developed to record the posture and movement of the cow. The timing and position of hoof placement and release was recorded using a pressure-sensitive mat, and a separation gate ensured that only one cow passed the system at a time (Figure 1).

The camera-pressure mat system was set up in the Institute for Agricultural and Fisheries Research farm in Ghent (Belgium), where about 80 Holstein-Friesian cows were milked twice daily in a $2 \times 3$ autotandem milking parlor. The camera-pressure mat system was installed in a 30-m-long alley located outside a barn. The measurement zone of the pressure-sensitive mat was a 1 -m-wide and 6 -m-long rigid measurement bridge with several protective layers of ethylene propylene diene monomer and rubber, which ensured flat support for the sensor mat on any surface (Maertens et al., 2011). The sensor itself (CIR Systems Inc., Havertown, PA) had an active surface $0.61 \mathrm{~m}$ wide and $4.88 \mathrm{~m}$ long with a square grid of 18,432 sensor elements. Measurements with the pressure-sensitive mat were done at 60 $\mathrm{Hz}$ over $15 \mathrm{~s}$. Each cow took 5 to $10 \mathrm{~s}$ to traverse the 6-m-long measurement bridge.
A Guppy F-080C camera (Allied Vision Technologies, Stadtroda, Germany) was installed in the alley to capture the movements of the cow when walking over the pressure mat. The camera was installed 2.5 $\mathrm{m}$ above the ground at a distance of $3.5 \mathrm{~m}$ from the pressure mat. The camera used a SV-03514 3.5-mm lens (VS Technology, Tokyo, Japan) and was focused at the center of the alley. It recorded at a resolution of $1,024 \times 768$ pixels with an average speed of 20 frames/s and covered the entire measurement zone in which the pressure mat was installed. All cows were equipped with collar radio frequency identification transponders (DeLaval, Tumba, Sweden) for identification.

\section{First Recordings}

In the first experiments, the measurements were operated by one person, who manually started the recording of the pressure mat when a cow passed through the separation gate. The pressure mat system then sent an electronic signal to the camera system, which triggered the camera software to start video recording. The recording of the pressure mat stopped automatically when no activity occurred on the system for 2.5 $\mathrm{s}$, which ensured the cow was out of the range of the camera. Every frame from the pressure mat and every image from the camera were saved with the exact elapsed time (ms) from the start of the recording. Because of the electronic signal sent out by the pressure mat system, the start of the recording for both systems was synchronized, with a synchronization error less than $16 \mathrm{~ms}$, and data obtained were combined in Matlab (R2009a, MathWorks, Natick, MA). Software was developed to record images, including the millisecond timestamp of the frames. The camera images were recorded to a video file (.avi format) and the timestamps stored in a text file.

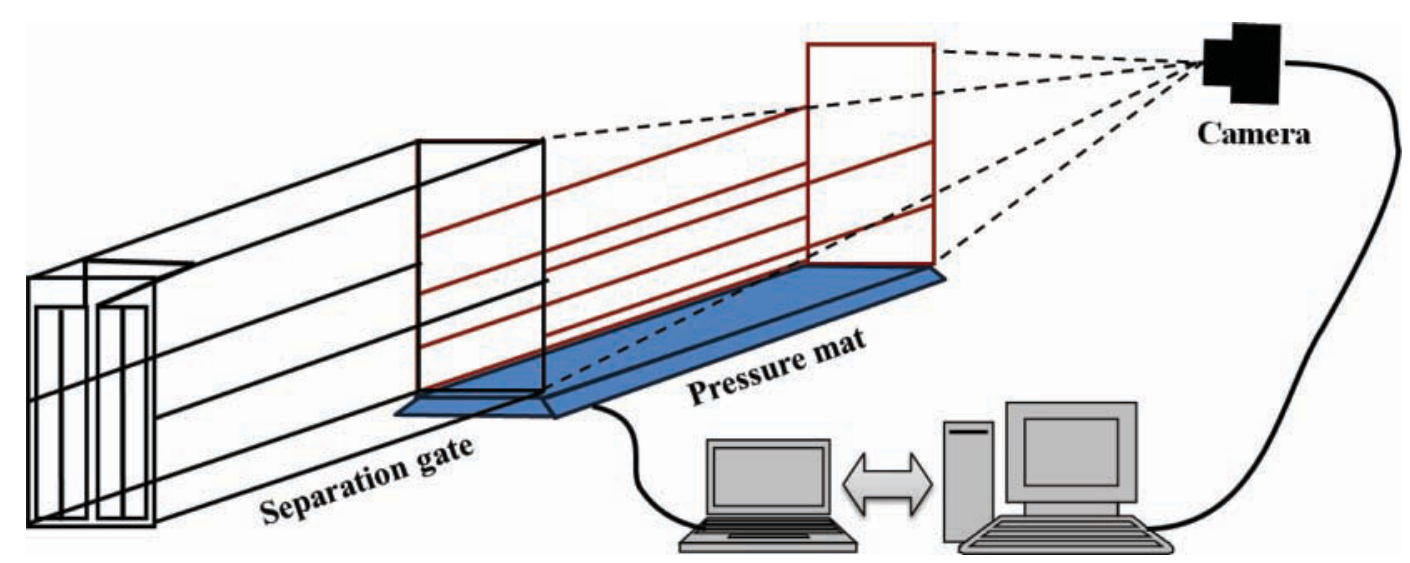

Figure 1. Schematic overview of the experiment setup, consisting of a camera system, a pressure-sensitive mat, and a separation gate. Color version available in the online PDF. 
Data collection with this system was performed once weekly over 3 consecutive weeks in October 2008 on 70 lactating Holstein cows in total. This resulted in 193 observations because not all cows were present on each recording day.

\section{Automatic Recordings}

After analysis of the recordings in October 2008, some improvements to the system were made to make continuous automatic recordings possible. To prevent the surface of the pressure mat from becoming too slippery in wet weather conditions, a roof was installed over the alley. This reduced the occurrence of shadows from direct sunlight on the image. In addition, a green curtain was installed as background to improve the contrast between the foreground and the background in the image.

The recording software was improved to cope with the changing light conditions that can occur throughout continuous experiments. The software was configured to alter the shutter time of the camera automatically until the overall brightness of the image was at a predefined level. This made recordings in full sunlight as well as half-light possible, keeping the brightness of the image constant. In addition, the recorded image was limited to a predefined region of interest, which reduced the data storage requirements of the system.

An improvement was made in the synchronization of the start of the recording. Whereas in the first experimental setup an operator was necessary to start the measurements, the improved setup used a signal from the separation gate to start the recordings. When a cow entered the measurement area, the separation gate read the cow number from its radio frequency identification transponder and sent an electronic signal to close the gate behind the cow. This electronic signal was read by both the pressure mat system and the camera system, which used this signal as trigger to start recording simultaneously. Both systems recorded for a maximum of $15 \mathrm{~s}$.

Data collection with the automatic system was performed on the same farm in Ghent (Belgium) continuously for a period of 5 wk in September and October 2009 on 75 individual lactating Holstein cows. In total, 2,219 measurements were performed because not all cows were present on each recording day.

\section{Visual Locomotion Scoring}

As a gold standard for the analysis of the calculated variables, the locomotion of the cows was visually scored from recorded video by 1 trained observer. Locomotion of all cows was scored twice weekly. The scoring method was based on the method of Winckler and Willen (2001), with a modification of the scoring scale according to the Lameness Workshop in December 2007 (Ghent, Belgium) based on the Welfare Quality project (Welfare Quality consortium) as described by van Nuffel et al. (2009). The scoring scale ranged from gait score (GS) 1 for sound cows to GS3 for severely lame cows.

\section{Data Combination and Image Analysis}

Using the timing information, which was stored in text files by both the pressure mat system and the camera system, the pressure mat data and the camera images were synchronized and could be visualized (Figure 2).

From the pressure mat data, the exact timing and position of placement of the hoof on the mat was determined. Using the timing information, the corresponding camera image was found. That image, together with the position information, was used for image processing to automatically calculate the touch angle (Figure 3 ). The same procedure was performed for the moment when the hoof was released from the pressure mat (release angle), combining both angles provided a new measurement designated "range of motion" (release angle - touch angle) in the fetlock joint for that stance phase of a designated leg.

Automatic calculation of the touch and release angles of a designated leg was performed using image processing techniques. First, the static background was removed from the lower part of the camera image (lower part of Figure 4). Image enhancement techniques were applied to remove noise in the image. After this, the $\mathrm{x}$ and $\mathrm{y}$ positions of the hoof in the image were determined from the pressure mat data (Figure 4). Starting from this hoof position, the rotation of the metacarpus (or metatarsus) bone was determined (line in Figure 4).

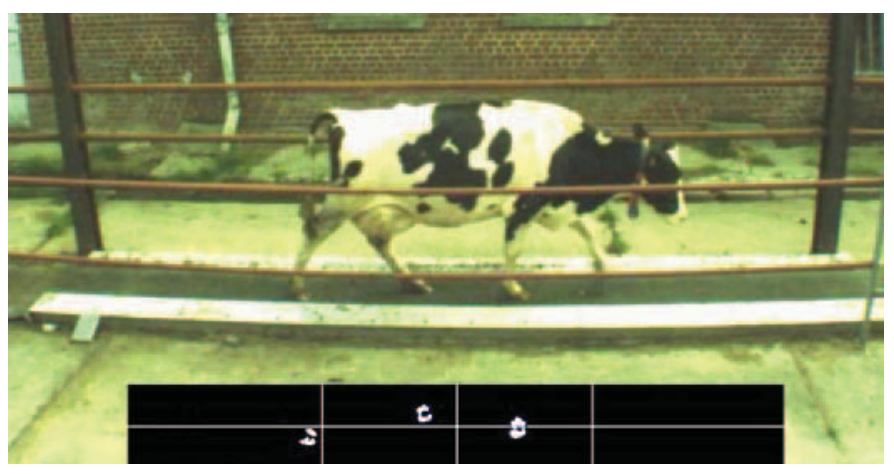

Figure 2. Visualization of the output of the pressure-sensitive mat combined with the corresponding camera image. Color version available in the online PDF. 


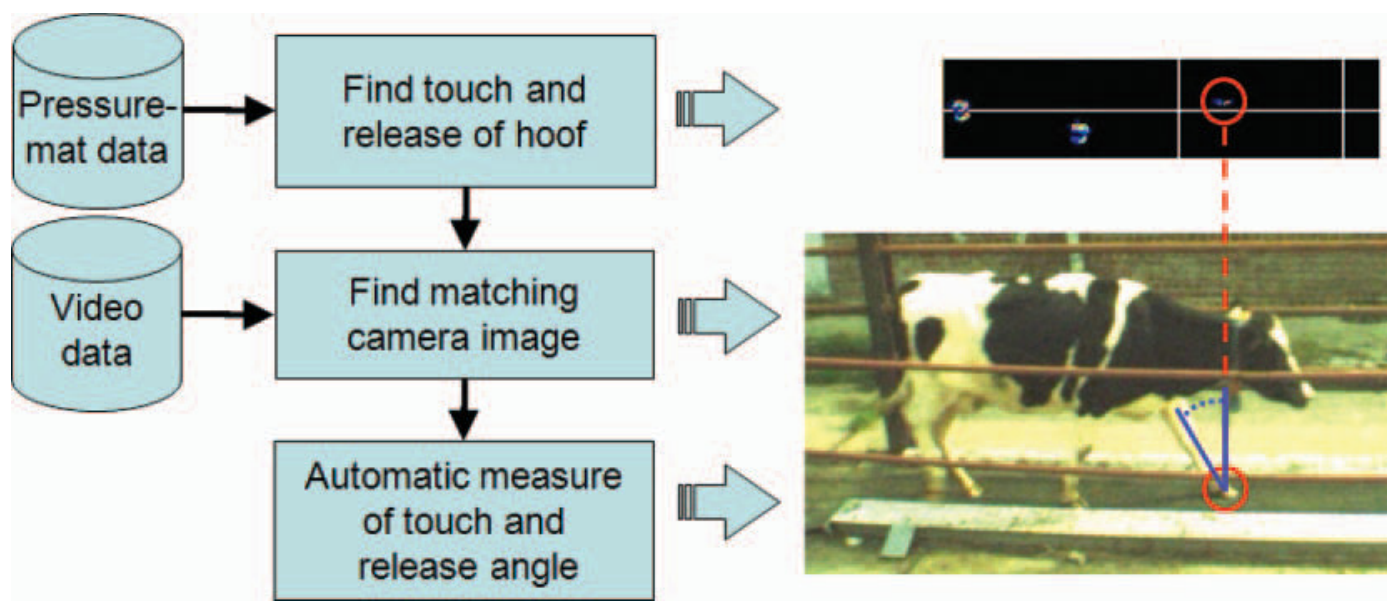

Figure 3. Flowchart of combining pressure and image data for calculation of touch and release angles. From the pressure mat data, the exact timing and position of placement of the hoof was determined. From the video data, the corresponding camera image was found. The image and position information were used to automatically calculate the touch angle. Color version available in the online PDF.

The rotation was calculated relative to a vertical line through the hoof, where a counterclockwise rotation was seen as a negative rotation.

\section{Statistical Analysis}

The Statistics Toolbox Software (version 7.1) from Matlab (R2009a, MathWorks) was used for statistical analysis. The Kruskal-Wallis and Wilcoxon rank-sum tests used in this research are nonparametric tests in which the assumption is that the measurements come from a continuous distribution, but not necessarily a normal distribution. Therefore, the tests were based on the analysis of the ranks of the data values, not the data values per se (Wilcoxon, 1945; Kruskal and Wallis, 1952). For the classification of the cows into different GS classes, quadratic discriminant analysis was used, because a nonnormal distribution was assumed for this test (McLachlan, 2004).

\section{RESULTS AND DISCUSSION}

\section{First Experimental Recordings}

Table 1 shows the results from a test on 3 cows. The range of motion was the complete rotation the leg makes while the hoof was in contact with the ground (release angle - touch angle). For cows 618 and 620, only 1 step from the right front and hind hoof was measured, because the second step was out of the range of the camera. For the other hooves, 2 steps were measured.

Visual inspection of the image processing showed that 1 measurement (indicated in the table) produced an incorrect result because too little contrast existed for the image processing algorithm. This result was ignored in the analysis, as was its resulting range of motion.
The median range of motion over all cows for each hoof was calculated. This was $52^{\circ} \pm 9.3^{\circ}$ for the right front hoof, $51^{\circ} \pm 4.4^{\circ}$ for the left front hoof, $56^{\circ} \pm 7.5^{\circ}$ for the right hind hoof, and $54^{\circ} \pm 9.3^{\circ}$ for the left hind hoof. The range of motion of each hoof of an individual cow was compared against these median values.

The right front hoof of cow 620 showed a large negative deviation $\left(-15^{\circ}\right)$ from the median value and the left hind hoof of cow 518 showed a large negative deviation $\left(-8^{\circ}\right)$. These negative deviations can be an indication for lameness (Bahr et al., 2008).

\section{Automatic Recordings}

From the recordings taken in September and October 2009, 2 wk were analyzed with 504 measurements. In

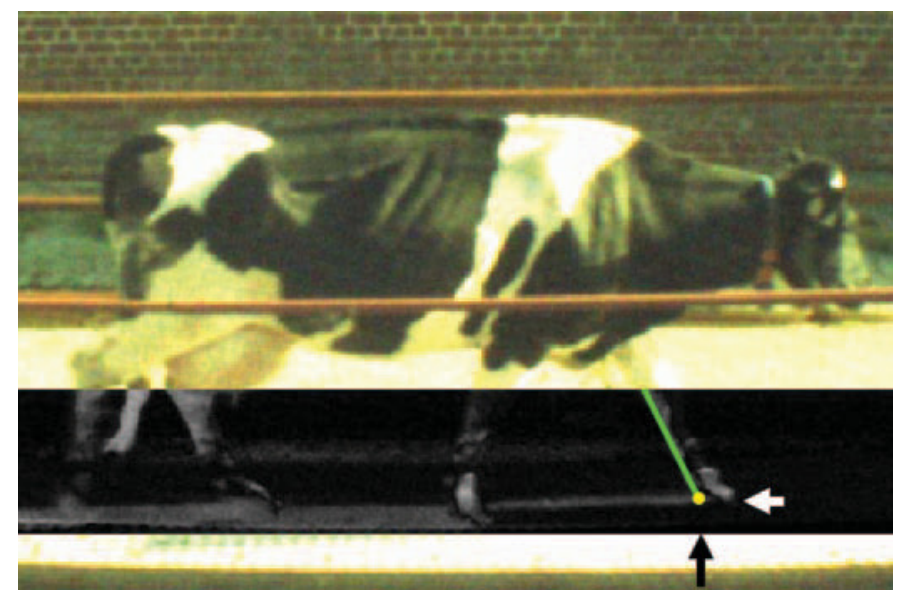

Figure 4. Example of image processing on a camera image. In the lower part of the image the background is removed. Arrows indicate the hoof position in the image determined from the pressure mat data. The line indicates the calculated rotation of the metacarpus bone. Color version available in the online PDF. 
Table 1. Automatically calculated touch and release angles of the metacarpus (front) and metatarsus (hind) bone of 3 cows with different gait scores ${ }^{1}$

\begin{tabular}{|c|c|c|c|c|c|c|c|}
\hline \multirow[b]{2}{*}{$\begin{array}{l}\text { Cow number/ } \\
\text { gait score }\end{array}$} & \multirow[b]{2}{*}{ Hoof } & \multicolumn{2}{|c|}{ Touch angles $\left({ }^{\circ}\right)$} & \multicolumn{2}{|c|}{ Release angles $\left(^{\circ}\right)$} & \multicolumn{2}{|c|}{$\begin{array}{l}\text { Range of } \\
\text { motion }\left({ }^{\circ}\right)\end{array}$} \\
\hline & & $\begin{array}{l}\text { First } \\
\text { step }\end{array}$ & $\begin{array}{l}\text { Second } \\
\text { step }\end{array}$ & $\begin{array}{l}\text { First } \\
\text { step }\end{array}$ & $\begin{array}{l}\text { Second } \\
\text { step }\end{array}$ & $\begin{array}{l}\text { First } \\
\text { step }\end{array}$ & $\begin{array}{l}\text { Second } \\
\text { step }\end{array}$ \\
\hline \multirow[t]{4}{*}{618 (gait score 1 ) } & Right front & -20 & & 33 & & 53 & \\
\hline & Left front & -30 & -22 & 24 & 25 & 54 & 47 \\
\hline & Right hind & -37 & & 34 & & 71 & \\
\hline & Left hind & -35 & -31 & 13 & 24 & 48 & 55 \\
\hline \multirow{4}{*}{620 (gait score 2) } & Right front & -12 & & 25 & & $37^{2}$ & \\
\hline & Left front & -24 & $-17^{3}$ & 27 & 23 & 51 & $40^{3}$ \\
\hline & Right hind & -36 & & 20 & & 56 & \\
\hline & Left hind & -37 & -33 & 33 & 31 & 70 & 64 \\
\hline \multirow[t]{4}{*}{518 (gait score 3 ) } & Right front & -33 & -17 & 26 & 34 & 59 & 50 \\
\hline & Left front & -26 & -14 & 26 & 29 & 52 & 43 \\
\hline & Right hind & -37 & -36 & 18 & 28 & 55 & 64 \\
\hline & Left hind & -35 & -27 & 18 & 19 & $53^{2}$ & $46^{3}$ \\
\hline
\end{tabular}

${ }^{1}$ Angles are measured in degrees relative to a vertical line through the hoof, where a counterclockwise rotation was seen as negative.

${ }^{2}$ Large negative deviation from median value.

${ }^{3}$ Incorrect measurements due to too little contrast.

total, 104 of the 504 recordings could not be used because of problems with the synchronization of the pressure mat and the camera system $(\mathrm{n}=35)$, or because of problematic light conditions such as too little light or too much shadow $(\mathrm{n}=10)$. Also, recordings where cows did not walk continuously were omitted $(\mathrm{n}=59)$. With 400 useful recordings (79.4\%) from 75 cows, each cow was recorded about 5 times within a period of 2 wk. The majority of cows $(\mathrm{n}=59)$ had between 5 and 8 correct recordings; however, 4 cows had no correct recordings during the 2 -wk period.

In each recording, all hoof placements were detected and the corresponding touch and release angles were measured. In total, 4,920 angles were measured, of which 221 (4.5\%) were considered inaccurate, based on thresholds and visual inspection, because of a lack of contrast in the images. About 11.7 accurate measurements were taken per recording. All 4,699 measurements were equally divided over the different legs (Table 2 ).

In the 400 recordings, 214 cows $(53.5 \%)$ were scored with GS1, 133 cows (33.3\%) were scored with GS2, and 37 cows $(9.3 \%)$ were scored with GS3. Sixteen cows $(4.0 \%)$ were not scored because the recording was stopped before a full stride was completed.

\section{Analysis of Lameness Indicators}

Group Analysis. In the group analysis, the kinematic data of the sound cows were compared with the data from the groups of cows with a higher degree of lameness to assess differences in gait, as in Buchner et al. (1993). Table 3 gives an overview of the median measured touch and release angles, together with the range of motion grouped per hoof by GS. Grouping of the front hooves and hind hooves between cows was based on the measured joint angles. This grouping was done because the assumed influence of lameness on the joint angles can occur on either side of the body. For example, when grouping all left front hooves, affected and unaffected hooves were grouped together. This will increase the variance of the data within the group and will have a negative effect on statistical comparison of the different groups. By analysis of the measured joint angles within each cow, the smaller front hoof joint angle (minimum) for a single cow can be grouped together with the smaller front hoof joint angles of the other cows, as was done in Pluk et al. (2010).

The touch angles of the front hooves were smaller than those of the hind hooves (Table 3). This was expected based on the anatomy of the cow (Villar et al., 2008). The reverse occurred for the release angles, summing to a similar range of motion for both.

In Figure 5, the median touch (a) and release angles (b) for the front hooves on the minimum side are shown in a box plot by GS. In Figure 5a all classes show a large amount of overlap, whereas Figure 5b shows

Table 2. Number of measurements of touch and release angles per hoof (\% in parentheses) and per cow from the automatic recordings

\begin{tabular}{lcc}
\hline Hoof & Measurements & $\begin{array}{c}\text { Measurements } \\
\text { per cow }\end{array}$ \\
\hline Left front & $1,203(25.6)$ & 16.0 \\
Right front & $1,154(24.6)$ & 15.4 \\
Left hind & $1,196(25.5)$ & 15.9 \\
Right hind & $1,146(24.4)$ & 15.3 \\
\hline
\end{tabular}



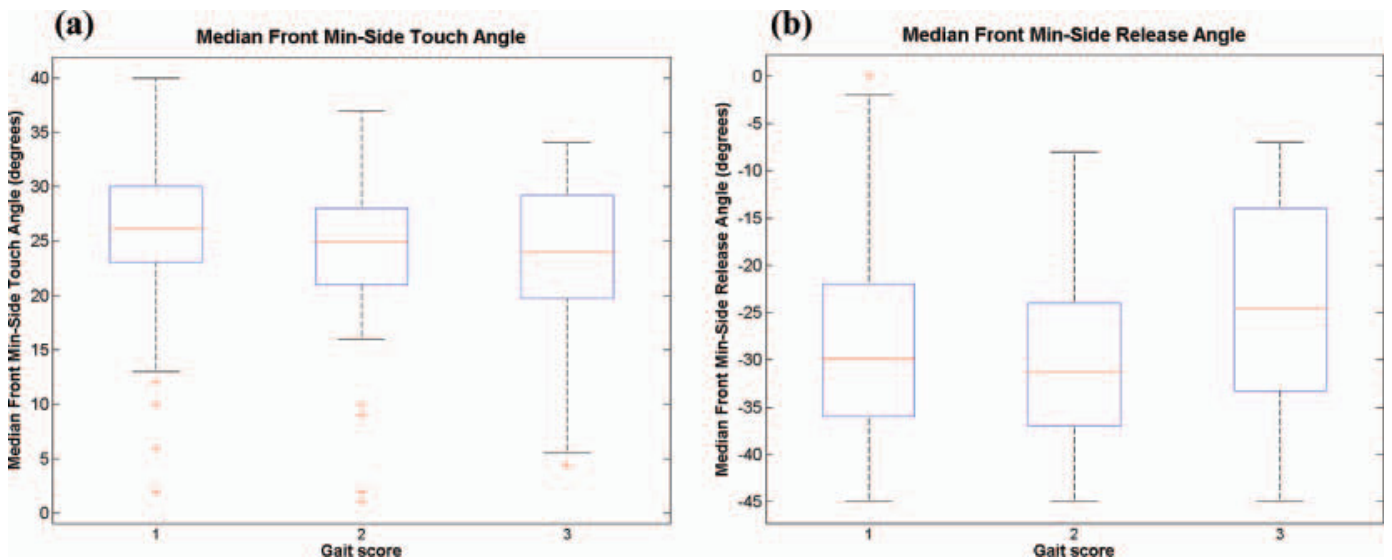

Figure 5. Measured median touch (a) and release (b) angles of the metacarpus bone on the minimum-side front hooves of the cow, grouped per gait score. Angles are measured in degrees relative to a vertical line through the hoof, where a counterclockwise rotation was seen as negative. Color version available in the online PDF.

changes between GS3 and GS1 or GS2. For both touch and release angles, a large amount of overlap existed between the different GS. Similar results were found in the touch and release angles of the front maximum side. Most researchers investigate the angle of the (fetlock) joints during a complete stride (Buchner et al., 1996; Keegan et al., 2000; Kramer et al., 2000), making comparison of absolute values with this research difficult.

Looking at the range of motion of the front hooves in Figure 6, it can be seen that only a small difference existed between GS1 and GS2, whereas the cows with GS3 had a smaller range of motion compared with the others. Adrian et al. (1977) and Taylor et al. (1966) reported range of movement of the fore fetlock of $40^{\circ}$ to $57^{\circ}$, which is supported by the findings in this research.

Kruskal-Wallis and Wilcoxon Rank-Sum Test Results. Using the Kruskal-Wallis test, the 3 GS were tested for significant differences with respect to their touch and release angles and range of motion. The results are shown in Table 4. A significant difference $(P<$ 0.05 ) was found between GS in the touch angles of the hind hooves on both minimum and maximum sides and in the front hoof on the minimum side. Also, significant differences were found in the release angles of the front hooves and in the range of motion of the front hooves $(P<0.05)$. The Kruskal-Wallis test did not indicate which GS were different.

Based on the results from the Kruskal-Wallis test, a Wilcoxon rank-sum test was performed to investigate which GS differed significantly from each other (Table $5)$. The touch angle from the front hoof on the maximum side and the release angles of both front hooves as well as both ranges of motion of the front hooves all showed a significant difference between GS3 and the other GS. The touch angle from the hind hoof on the maximum side showed a significant difference between

Table 3. Automatically measured median touch and release angles and range of motion (SD in parentheses) of the metacarpus (front) and metatarsus (hind) bone grouped per hoof by gait score ${ }^{1}$

\begin{tabular}{|c|c|c|c|c|}
\hline $\begin{array}{l}\text { Gait } \\
\text { score }\end{array}$ & Hoof & $\begin{array}{l}\text { Median touch } \\
\text { angle }\left(^{\circ}\right)\end{array}$ & $\begin{array}{l}\text { Median release } \\
\text { angle }\left({ }^{\circ}\right)\end{array}$ & $\begin{array}{l}\text { Median range } \\
\text { of motion }\left({ }^{\circ}\right)\end{array}$ \\
\hline \multirow[t]{4}{*}{1} & Minimum front & $-26.3(5.73)$ & $16.0(9.09)$ & $44.0(9.61)$ \\
\hline & Maximum front & $-37.0(5.43)$ & $30.0(9.54)$ & $58.5(10.63)$ \\
\hline & Minimum hind & $-36.0(4.52)$ & $7.0(7.32)$ & $43.0(7.69)$ \\
\hline & Maximum hind & $-41.0(2.55)$ & $18.0(10.72)$ & $56.0(10.54)$ \\
\hline \multirow[t]{4}{*}{2} & Minimum front & $-25.0(6.71)$ & $17.0(9.98)$ & $43.0(11.26)$ \\
\hline & Maximum front & $-37.0(6.29)$ & $31.3(9.61)$ & $60.0(10.55)$ \\
\hline & Minimum hind & $-34.0(5.67)$ & $7.0(6.69)$ & $43.0(8.13)$ \\
\hline & Maximum hind & $-40.0(2.98)$ & $17.3(9.41)$ & $54.5(9.81)$ \\
\hline \multirow[t]{4}{*}{3} & Minimum front & $-24.0(6.96)$ & $10.0(10.74)$ & $37.5(10.66)$ \\
\hline & Maximum front & $-34.0(4.99)$ & $24.5(11.25)$ & $53.0(12.19)$ \\
\hline & Minimum hind & $-34.0(4.98)$ & $5.0(6.81)$ & $41.5(7.07)$ \\
\hline & Maximum hind & $-40.0(2.82)$ & $20.5(10.11)$ & $50.5(9.62)$ \\
\hline
\end{tabular}

${ }^{1}$ Angles are measured in degrees relative to a vertical line through the hoof, where a counterclockwise rotation was seen as negative. 

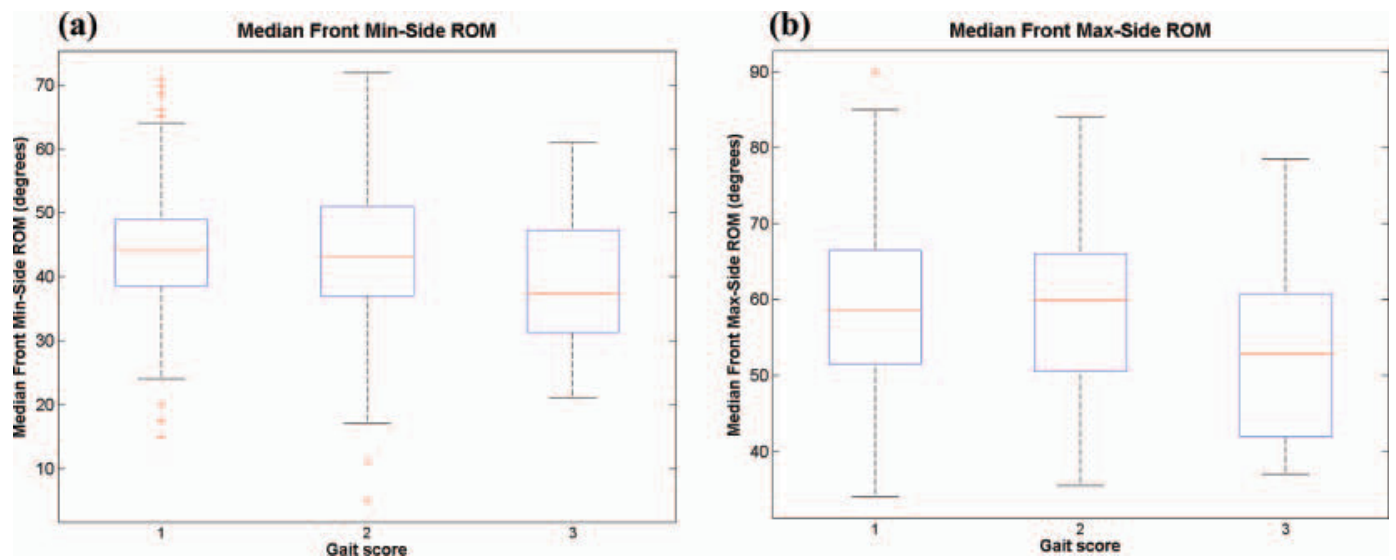

Figure 6. Measured median range of motion (ROM) angles $\left({ }^{\circ}\right)$ of the metacarpus bone on the minimum (a) and maximum (b) side front hooves of the cow, grouped by gait score. Color version available in the online PDF.

GS1 and the other GS, whereas the touch angles from both hooves on the minimum side show a significant difference between GS1 and GS2. Keegan et al. (2000) and Kramer et al. (2000) observed decreased extension of the fetlock joint in horses with induced lameness or pain. This corresponds with the decrease in the touch angles observed in this research.

Because the above data show significant differences between the different GS, these variables might be useful for classification of lameness. Kramer et al. (2009) used a fuzzy logic approach to do a binary classification of lameness based on several measurements of feed and water intake and milk yield. Their classification had a high specificity ( 75.3 to $75.9 \%$ ) but also a high error rate (98.9 to $99.5 \%)$. Keegan et al. (2003) used neural networks for classification of lameness in horses based on head position and the right forelimb foot. They reached a correct classification percentage of $85 \%$ on a small number of horses (24 in total). Poursaberi et al. (2010) reached $96 \%$ correct classification using only the back posture of the cow and a linear threshold.

Table 4. Results ( $P$-values) of the Kruskal-Wallis test for significant differences between the 3 gait scores with respect to the touch angles, release angles, and range of motion

\begin{tabular}{lllr}
\hline Angle & Hoof & & $P$-value \\
\hline Median touch angle & Front & Maximum & 0.0541 \\
& & Minimum & 0.0077 \\
& Hind & Maximum & 0.0019 \\
Median release angle & & Minimum & 0.0003 \\
& \multirow{2}{*}{ Front } & Maximum & 0.0462 \\
& \multirow{2}{*}{ Hind } & Minimum & 0.0340 \\
Median range of motion & \multirow{2}{*}{ Front } & Minimum & 0.2824 \\
& \multirow{2}{*}{ Hind } & Maximum & 0.9393 \\
& & Maximum & 0.0043 \\
& & Minimum & 0.0272 \\
& & & 0.2718 \\
\hline
\end{tabular}

In our research, quadratic discriminant analysis was used for classification between 2 or 3 groups of GS, based on the combination of all measured variables. The correct classification percentage for each individual variable is shown in Table 6 , together with the correct classification percentage of the combined model of all variables.

Group (a) in Table 6 shows the results for a classification between GS1 on one side and GS2 and GS3 on the other side. The touch angles on the front minimum side $(57.7 \%)$ and both touch angles of the hind hooves (58.6 and 58.0\%) gave the best classification results between GS1 and GS2 or GS3. The combined model of all variables performed only $7.1 \%$ better than the individual variables in classification between GS1 and GS2 or GS3. Correct classification between GS1 and GS2 or GS3 is important for detection of developing lameness in an early stage. Timely detection would allow for faster treatment and prevent the lameness from developing into a chronic condition (Clarkson et al., 1996).

Group (b) in Table 6 shows the results for a classification between GS1 and GS2 on one side and GS3 on the other side. The range of motion of both front hooves (62.0 and $61.3 \%$ ) together with the touch angle on the front maximum side $(60.4 \%)$ and the release angles of both front hooves (60.8 and 59.4\%) gave the best classification results of the individual variables. Combining all variables into a single classification model yielded a considerable improvement in classification (81.5\%).

Group (c) in Table 6 shows the results for a classification between all 3 GS. The range of motion of both front hooves (42.1 and $42.8 \%$ ) together with the release angle of both front hooves (41.7 and $42.0 \%$ ) and the touch angle on the hind maximum side $(41.1 \%)$ performed best in classification using individual variables. Again, the combination of all variables for classification yielded 
Table 5. Results ( $P$-values) of the Wilcoxon Rank-sum test for significant differences between gait scores (GS) with respect to the touch angles, release angles, and range of motion

\begin{tabular}{llcc}
\hline Parameter & & GS2 & GS3 \\
\hline Median touch angle front maximum & GS1 & 0.7072 & 0.0262 \\
Median touch angle front minimum & GS2 & & 0.0185 \\
& GS1 & 0.0044 & 0.0579 \\
Median touch angle hind maximum & GS2 & & 0.8789 \\
& GS1 & 0.0009 & 0.0453 \\
Median touch angle hind minimum & GS2 & & 0.9028 \\
& GS1 & 0.0001 & 0.0620 \\
Median release angle front maximum & GS2 & & 0.5272 \\
Median release angle front minimum & GS1 & 0.6523 & 0.0170 \\
Median range of motion front maximum & GS2 & & 0.0245 \\
Median range of motion front minimum & GS1 & 0.4586 & 0.0235 \\
& GS2 & & 0.0106 \\
\hline
\end{tabular}

an improvement $(65.4 \%)$ over the individual variables. Compared with the binary classification results of Kramer et al. (2009), the error rate in this research was considerably lower (20 to $35 \%$ ), but the specificity was also lower. Back posture (Poursaberi et al., 2010) performed significantly better as a stride variable in the classification of different degrees of lameness. All results in this section supported the previously shown results from both the Kruskal-Wallis test and the Wilcoxon rank-sum test.

\section{Individual Analysis}

The above analyses were based on the assumption that the effect of lameness on the measured variables was similar in all cows considered. Because differences exist in individual animals in their "normal" walking pattern (because lameness affects walking pattern), analysis on an individual level was performed. Animals were compared on an individual level (within animal), using the animal as its own control. We assumed that this would be beneficial in detecting changes in gait from sound to lame. For example, studies on horses with induced lameness report within-animal changes in gait variables (Buchner et al., 1996; Keegan et al., 2001).

In the experiments of September and October 2009, 64 cows were present in 4 or more observations. Fortytwo of these cows had a variation in GS in one or more of the observations, leaving 22 cows with a constant GS throughout the study. A total of 3 cows had an increase in GS from 1 to 3 and 1 cow had a decrease in GS from 3 to 1 . All other cows with a variation in GS had a change of only 1 level of lameness.

Because range of motion and the release angle of both front hooves performed the best in classification, these variables were selected for the individual analysis. All cows were grouped into 5 classes with respect to their

Table 6. Correct classification percentage (minimum and maximum) of classification between different gait scores (GS; 1 to 3 ), where classification was based on individual variables [touch angle (TA), release angle (RA), and range of motion (ROM)] as well as a combined model of all variables

\begin{tabular}{|c|c|c|c|c|c|c|c|c|c|c|c|c|c|}
\hline Group $^{1}$ & \multicolumn{2}{|c|}{ TA front } & \multicolumn{2}{|c|}{ TA hind } & \multicolumn{2}{|c|}{ RA front } & \multicolumn{2}{|c|}{ RA hind } & \multicolumn{2}{|c|}{ ROM front } & \multicolumn{2}{|c|}{ ROM hind } & Combined \\
\hline (a) GS1 vs. (GS2 and GS3) & $57.7^{2}$ & 49.0 & $58.6^{2}$ & $58.0^{2}$ & 50.5 & 55.3 & 53.7 & 48.4 & 53.7 & 51.1 & 51.4 & 52.3 & $65.7^{2}$ \\
\hline (c) GS1 vs. GS2 vs. GS3 & 40.0 & 39.0 & 39.3 & $41.1^{2}$ & $41.7^{2}$ & $42.0^{2}$ & 34.9 & 38.2 & $42.1^{2}$ & $42.8^{2}$ & 37.7 & 37.1 & $65.4^{2}$ \\
\hline
\end{tabular}

${ }^{1} \mathrm{a}=$ classification between GS1 on one side and GS2 and GS3 on the other side; $\mathrm{b}=$ classification between GS1 and GS2 on one side and GS3 on the other side; and $\mathrm{c}=$ classification between all 3 gait scores.

${ }^{2}$ Best classification results. 
Table 7. Average of within-cow variance (degrees) for front foot range of motion and front release angles on both body sides for cows with a constant gait score throughout the measurement

\begin{tabular}{lccccc}
\hline & \multicolumn{2}{c}{ Front range of motion $\left(^{\circ}\right)$} & & \multicolumn{2}{c}{ Front release angle $\left(^{\circ}\right)$} \\
\cline { 2 - 3 } \cline { 5 - 6 } Gait score & Minimum & Maximum & & Minimum & Maximum \\
\hline 1 & 7.01 & 8.60 & & 8.49 & 6.94 \\
2 & 6.82 & 8.41 & & 9.31 & 7.18 \\
\hline
\end{tabular}

lameness scores throughout the study. The cows with a constant GS throughout the experiments were grouped by GS. No cows had a constant GS3, so 2 classes (GS1 and GS2) remained. The cows with a changing GS were grouped based on their lameness evolution: class GS12 for cows with an evolution from GS1 to GS2 or vice versa $(\mathrm{n}=31)$; class GS23 for cows with an evolution from GS2 to GS3 or vice versa $(\mathrm{n}=7)$; and class GS13 for cows with an evolution from GS1 to GS3 or vice versa $(\mathrm{n}=4)$.

Changes in Within-Cow Variance. For the cows with a constant GS, the variance of the selected variables within an individual cow was calculated and is shown in Table 7 . These values are smaller than the calculated variance on the group level in Table 3, indicating that analysis on an individual basis would produce more precise results, as expected for living organisms.

Looking at the cows with an evolution in lameness, the hypothesis was that a change in GS would lead to an increase in the within-cow variance for one or more of the selected variables. This hypothesis was tested by first calculating the within-cow variance for the observations in which the cow had a constant GS. That variance was compared with the within-cow variance for all experiments of that cow. The percentage of cows that supported this hypothesis is shown in Table 8. In total, in the 3 classes of changing GS, $83.3 \%$ of the cows showed an increase in within-cow variance for at least 1 variable whenever the GS changed. This shows that by monitoring the variance of these variables, changes in GS can be detected in a large percentage of cows. An increase in variance was also seen by Buchner et al. (1996), who reported a decrease in the extension of the fetlock joint of the lame limb and a compensatory increase in the contralateral limb. Other gait variables such as vertical head movement show a significant increase in variance with increasing lameness (Keegan et al., 2001).

Changes in Variables. A stronger hypothesis that can be deduced from the results on the group analysis was that an increase in GS would lead to a decrease in range of motion or an increase in the release angle of the front hooves. This hypothesis was tested for the different classes of cows. The results in Table 9 indicate the percentage of cows that confirm the hypothesis. The total confirmation rate within all 3 groups of animals with a changing GS was $76.2 \%$. Results from Keegan et al. (2000) and Kramer et al. (2000) also show a decrease in range of motion of the fetlock joint. Both studies showed a decrease in fetlock joint extension with induced lameness in horses, which leads to a decreased range of motion of the fetlock joint.

\section{Potential of the System}

Changes in GS can be detected by monitoring fetlock joint angles over a longer period. In practice, the system would be able to measure and analyze joint angles automatically after milking in an automated milking system. Based on our analysis, the system could signal the farmer about a change in the lameness condition of an individual cow. This would give the farmer the opportunity to reduce the time until a lameness case is treated.

Lesions in an individual leg will not only affect the steps of that leg, but also have an influence on the gait of all legs. That influence was used in the analysis

Table 8. Percentage of cows that confirm the hypothesis that a change in gait score (GS) would lead to an increase in within-cow variance for one or more of the selected variables

\begin{tabular}{lcccccc}
\hline & \multicolumn{2}{c}{ Front range of motion } & & \multicolumn{2}{c}{ Front release angle } & \\
\cline { 2 - 3 } Group $^{1}$ & Minimum & Maximum & & Minimum & Maximum & Combined \\
\hline GS12 & 54.8 & 48.4 & & 51.6 & 45.2 & 90.3 \\
GS23 & 71.4 & 57.1 & & 57.1 & 42.9 & 71.4 \\
GS13 & 25.0 & 50.0 & & 25.0 & 25.0 & 50.0 \\
Total & 54.8 & 50.0 & & 50.0 & 42.9 & 83.3 \\
\hline
\end{tabular}

${ }^{1}$ GS12 = cows with an evolution from GS1 to GS2 or vice versa; GS23 = cows with an evolution from GS2 to GS3 or vice versa; and GS13 = cows with an evolution from GS1 to GS3 or vice versa. 
Table 9. Percentage of cows that confirm the hypothesis that an increase in gait score (GS) would lead to a decrease in range of motion or an increase in release angle of the front hooves

\begin{tabular}{lccc}
\hline Group $^{1}$ & $\begin{array}{c}\text { Front range } \\
\text { of motion }\end{array}$ & $\begin{array}{c}\text { Front release } \\
\text { angle }\end{array}$ & Combined \\
\hline GS12 & 58.1 & 61.3 & 74.2 \\
GS23 & 71.4 & 42.9 & 71.4 \\
GS13 & 50.0 & 100.0 & 100.0 \\
Total & 59.5 & 61.9 & 76.2 \\
\hline
\end{tabular}

${ }^{1}$ GS12 = cows with an evolution from GS1 to GS2 or vice versa; GS23 = cows with an evolution from GS2 to GS3 or vice versa; and GS13 = cows with an evolution from GS1 to GS3 or vice versa.

of this research to make the lameness detection more sensitive. A drawback of that influence is that it makes it harder to detect the actual affected leg. Rajkondawar et al. (2002) and Tasch and Rajkondawar (2004) investigated ground reaction forces under each of the hooves, and Rushen et al. (2007) measured weight distribution to identify the problematic limb. In this research no information was available about the problematic leg, so identification of the affected leg could not be investigated. Future research should focus specifically on identifying the differences between the legs and improving data analysis to detect affected legs or even lameness type.

\section{CONCLUSIONS}

The system described has proven reliable for continuous automatic recordings necessary for the analysis of changes in variables over a long period. With the described combination of a camera system and a pressure-sensitive mat that records data in a synchronized manner, an algorithm for the automatic calculation of touch and release angles and range of motion was developed. In the group analysis, these variables showed differences between the different GS. Furthermore, classification results indicated early detection of lameness. Range of motion and release angle of the front hooves are the most important variables for lameness detection. By monitoring the variance of range of motion and release angle of the front hooves of individual cows and by monitoring a decrease in the range of motion or an increase in the release angle of the front hooves, changes in GS could be automatically detected in a large percentage of the cows.

\section{REFERENCES}

Adrian, M., B. Grant, M. Ratzlaff, J. Ray, and C. Bolulton. 1977. Electrogoniometric analysis of equine metacarpophalangeal joint lameness. Am. J. Vet. Res. 38:431-435.

Bahr, C., A. Koppenol, T. Leroy, X. Song, A. Pluk, E. Vranken, W. Maertens, J. Vangeyte, A. Van Nuffel, B. Sonck, and D. Berckmans. 2008. Dairy cow hoof movement analysis by vision tech- niques. Page 74 in 4th International Workshop on the Assessment of Animal Welfare at Farm and Group Level, WAFL 2008, Ghent, Belgium. Ponsen en Looijen, Wageningen, the Netherlands.

Booth, C. J., L. Warnick, Y. Grohn, D. Maizon, C. Guard, and D. Janssen. 2004. Effect of lameness on culling in dairy cows. J. Dairy Sci. 87:4115-4122.

Buchner, F., J. Kastner, D. Girtler, and P. Knezevic. 1993. Quantification of hind limb lameness in the horse. Acta Anat. (Basel) 146:196-199.

Buchner, H. H., H. Savelberg, H. Schamhardt, and A. Barneveld. 1996. Limb movement adaptations in horses with experimentally induced fore- or hindlimb lameness. Equine Vet. J. 28:63-70.

Clarkson, M. J., D. Downham, W. Faull, J. Hughes, F. Manson, J. Merritt, R. Murray, W. Russell, J. Sutherst, and W. Ward. 1996. Incidence and prevalence of lameness in dairy cattle. Vet. Rec. 138:563-567.

Flower, F. C., D. Sanderson, and D. Weary. 2005. Gait characteristics of dairy cattle with and without hoof pathologies. J. Dairy Sci. 88:3166-3173.

Flower, F. C., and D. Weary. 2006. Effect of hoof pathologies on subjective assessments of dairy cow gait. J. Dairy Sci. 89:139-146.

Green, L. E., V. Hedges, Y. Schukken, R. Blowey, and A. Packington. 2002. The impact of clinical lameness on the milk yield of dairy cows. J. Dairy Sci. 85:2250-2256.

Herlin, A. H., and A. Drevemo. 1997. Investigation of locomotion of dairy cows by use of high speed cinematography. Equine Vet. J. Suppl. 23:106-109.

Keegan, K. G., S. Arafat, M. Skubic, D. Wilson, and J. Kramer. 2003. Detection of lameness and determination of the affected forelimb in horses by use of continuous wavelet transformation and neural network classification of kinematic data. Am. J. Vet. Res. 64:1376-1381.

Keegan, K. G., R. Pai, D. Wilson, and B. Smith. 2001. Signal decomposition method of evaluating head movement to measure induced forelimb lameness in horses trotting on a treadmill. Equine Vet. J. 33:446-451.

Keegan, K. G., D. Wilson, B. Smith, and D. Wilson. 2000. Changes in kinematic variables observed during pressure-induced forelimb lameness in adult horses trotting on a treadmill. Am. J. Vet. Res. 61:612-619.

Kramer, E., D. Cavero, E. Stamer, and J. Krieter. 2009. Mastitis and lameness detection in dairy cows by application of fuzzy logic. Livest. Sci. 125:92-96.

Kramer, J., K. Keegan, D. Wilson, B. Smith, and D. Wilson. 2000. Kinematics of the hind limb in trotting horses after induced lameness of the distal intertarsal and tarsometatarsal joints and intra-articular administration of anesthetic. Am. J. Vet. Res. 61:1031-1036.

Kruskal, W., and W. Wallis. 1952. Use of ranks in one-criterion variance analysis. J. Am. Stat. Assoc. 47:583-621.

Maertens, W., J. Vangeyte, J. Baert, A. Jantuan, S. De Campeneere, A. Pluk, G. Opsomer, S. Van Weyenberg, and A. Van Nuffel. 2011. Development of a real time cow gait tracking and analyzing tool to asses lameness using a pressure sensitive walkway: The GAITWISE system. Biosystems Eng. 110:29-39.

McLachlan, G. 2004. Discriminant Analysis and Statistical Pattern Recognition. John Wiley \& Sons, Hoboken, NJ.

Meyer, S. W. 2007. Gait pattern of heifers before and after claw trimming: A high-speed cinematographic study on a treadmill. J. Dairy Sci. 90:670-676.

Peake, K. A., A. Biggs, C. Argo, R. Smith, R. Christley, J. Routly, and H. Dobson. 2011. Effects of lameness, subclinical mastitis and loss of body condition on the reproductive performance of dairy cows. Vet. Rec. 168:301.

Pluk, A., C. Bahr, T. Leroy, A. Poursaberi, X. Song, E. Vranken, W. Maertens, A. Van Nuffel, and D. Berckmans. 2010. Evaluation of step overlap as an automatic measure in dairy cow locomotion. Trans. ASABE 53:1305-1312.

Poursaberi, A., C. Bahr, A. Pluk, A. Van Nuffel, and D. Berckmans. 2010. Real-time automatic lameness detection based on back posture extraction in dairy cattle: Shape analysis of cow with image processing techniques. Comput. Electron. Agric. 74:110-119. 
Rajkondawar, P., U. Tasch, A. Lefcourt, B. Erez, R. Dyer, and M. Varner. 2002. A system for identifying lameness in dairy cattle. Appl. Eng. Agric. 18:87-96.

Rushen, J., E. Pombourcq, and A. de Passillé. 2007. Validation of two measures of lameness in dairy cows. Appl. Anim. Behav. Sci. 106:173-177.

Scott, G. B. 1989. Changes in limb loading with lameness for a number of Friesian cattle. Br. Vet. J. 145:28-38.

Sprecher, D. J., D. Hostetler, and J. Kaneene. 1997. A lameness scoring system that uses posture and gait to predict dairy cattle reproductive performance. Theriogenology 47:1179-1187.

Tasch, U., and P. Rajkondawar. 2004. The development of a SoftSeparator ${ }^{\mathrm{TM}}$ for a lameness diagnostic system. Comput. Electron. Agric. 44:239-245.

Taylor, B. M., C. Tipton, M. Adrian, and P. Karpovich. 1966. Actions of certain joints in the legs of the horse recorded electrogoniometrically. Am. J. Vet. Res. 27:85-89.

Thomsen, P. T., L. Munksgaard, and F. Togersen. 2008. Evaluation of a lameness scoring system for dairy cows. J. Dairy Sci. 91:119126. van Nuffel, A., M. Sprenger, F. Tuyttens, and W. Maertens. 2009. Cow gait scores and kinematic gait data: Can people see gait irregularities? Anim. Welf. 18:433-439.

Villar, J. M., A. Spadari, V. Billi, V. Desini, and A. Santana. 2008. Biomechanics in young and adult italian standardbred trotter horses in real racing conditions. Vet. Res. Commun. 32:367-376.

Warnick, L. D., D. Janssen, C. Guard, and Y. Grohn. 2001. The effect of lameness on milk production in dairy cows. J. Dairy Sci. 84:1988-1997.

Whay, H., and D. Main. 1999. "The way cattle walk" steps towards lameness management. Cattle Pract. 7:357-364.

Wilcoxon, F. 1945. Individual comparisons by ranking methods. Biom. Bull. 1:80-83.

Winckler, C., and S. Willen. 2001. The reliability and repeatability of a lameness scoring system for use as an indicator of welfare in dairy cattle. Acta Agric. Scand. A Anim. Sci. 30:103-107. 